\title{
Analysis of Siting Criteria of Overseas Geological Repository (I): Geology
}

\section{국외 심지층 처분장 부지선정기준 분석 (I) : 지질}

Haeryong Jung ${ }^{1 *}$, Hyun-Joo Kim ${ }^{1}$, Min Jung Kim² ${ }^{2}$ Jae-Yeol Cheong ${ }^{1}$, Yi-Yeong Jeong ${ }^{1}$ and Eun Yong Lee ${ }^{1}$ ${ }^{1}$ Korea Radioactive-wate Management Corporation, 989-111 Daedeokdaero, Yuseong-gu, Daejeon, Korea ${ }^{2}$ NEXGEO Inc., 5th Floor, Junghwa-building, 16-15, Garakbon-dong, Songpa-gu, Seoul, Korea

정해룡 ${ }^{1 *}$, 김현주 ${ }^{1}$, 김민정 ${ }^{2}$, 정재열 ${ }^{1}$, 정의영 ${ }^{1}$, 이은용 ${ }^{1}$

1 한국방사성폐기물관리공단, 대전시 유성구 대덕대로 989-111

2 (주) 넥스지오, 서울시 송파구 가락본동 16-15 정화빌동 5층

(Received February 05, 2012 / Revised February 13, 2012 / Approved September 11, 2012)

Geology, hydrogeology, and geochemistry are the main technical siting factors of a geological repository for spent nuclear fuels. This paper focused on how rock's different geological conditions, such as topography, soils, rock types, structural geology, and geological events, influence the functions of the geological repository. In the context, the site selection criteria of various countries were analyzed with respect to the geological conditions. Each country established the criteria based on its important geological backgrounds. For example, it was necessary for Sweden to take into account the effect of ice age on the land uplift and sea level change, whereas Japan defined seismic activity and volcanism as the main siting factors of the geological repository. Therefore, the results of the paper seems to be helpful in preparing the siting criteria of geological repository in Korea.

Key words: Geological disposal, Repository, Geology, Siting factors, Criteria

본 연구에서는 심지층 처분장 부지선정 시에 고려되는 요소를 지질, 수리지질, 지화학 등으로 분류하고 그 첫 번째 단계로 지질분야의 세부 항목을 지형, 토양층, 암종, 구조지질, 역학적 안정성, 지질학적사건으로 분류하였으며, 이들 항목에 대한 국 외 기준분석을 수행하였다. 부지선정요소(Siting factor)에 대한 기준(Criteria)은 각 국가의 처한 지질환경에 따라 다른 조건 혹은 값을 제시하고 있다. 화산 및 지진활동이 빈번한 일본에서는 이에 대한 기준을 상대적으로 자세히 기술하고 있으며, 빙 하작용이 예상되는 스웨덴에서는 빙하작용에 의한 지반 융기 - 침식에 대한 영향을 상세히 분석하였다. 따라서, 본 논문 결과 는 향후 국내의 심지층 처분장 부지선정 기준 수립시에 중요한 참고자료로 활용될 수 있을 것으로 판단된다.

중심단어: 심지층 처분, 처분장, 지질, 부지선정요소, 기준

*Corresponding Author . E-mail: nohul@krmc.or.kr, Tel: +82.42.601-5314 


\section{1. 서 론}

2009년 방사성폐기물관리 전담기관인 한국방사성폐기 물관리공단(이하 “공단”)이 설립된 이후, 2010년부터 사 용후핵연료 처분을 위한 “심지층 처분 한반도 지질환경 평가기술 개발"과제를 시작하였다. “심지층 처분 한반도 지질환경 평가기술 개발”과제에서는 전국토를 대상으로 사용후핵연료 처분을 위한 장기안정성 요소(단층, 지진, 화산, 융기·침강 등) 및 심부환경 정량화 작업을 수행하 고 있다. 또한, 심부환경에 대한 평가기술 개발을 시작하 였으며, 지질환경 평가를 위한 지질정보 데이터베이스 시 스템 구축을 개시하였다. 공단에서는 "심지층 처분 한반 도 지질환경 평가기술 개발”과제의 일환으로 심지층 처 분장 확보프로그램을 운영 중인 국가들을 중심으로 "국 외 처분시설 부지선정 프로그램 분석 보고서”를 발간하 였다[1]. 이 보고서에서는 IAEA[2] 및 심지층 처분장 부 지선정 작업을 수행하고 있는 8개 국가(스웨덴, 핀란드, 프랑스, 스위스, 독일, 영국, 미국, 일본)들에 대한 부지 선정 절차를 단계별로 구분하였다. 특히, 심지층 처분장 부지에 대한 신청서를 제출한 스웨덴에 대해서는 각 단 계별 평가 사례를 상세히 분석하여, 향후 벤치마킹 사례 로 삼고자 하였다.

심지층 처분장 부지선정 절차는 〈계획단계〉와 〈사업 단계〉로 구분 할 수 있다. 〈계획단계>에서는 처분원칙 과 부지선정 프로그램을 제시하게 되고, 〈사업단계〉에서 는 절차에 따른 부지선정 작업을 수행하게 된다. 또한 부 지선정 〈사업단계〉는 공모제와 지정고시제로 구분 할 수 있으며, 지정고시제는 전 국토를 대상으로 처분안전성에 대한 기술적 고려사항을 먼저 검토하여 부지를 좁혀가는 방법으로서 국가 별로 3 4단계로 절차를 구분하고 있다. 이들 국가에서는 〈사업단계〉별로 부지선정요소에 대해 각기 다른 기준(Criteria)을 적용하고 있다.

하지만 국내에서는 아직 심지층 처분장 부지확보 프로그 램이 확정되지 않아 부지선정 절차 및 이와 관련된 부지선 정 기준 등이 설정되지 못하고 있는 실정이다. 따라서, 본 논문에서는 심지층 처분장 부지선정 작업에 적용되는 기준 등에 대한 해외사례 분석을 통하여 향후 국내에 적용가능한 부지선정 기준 설정에 활용하고자 하였다.

본 연구에서는 심지층 처분장 부지선정 시에 고려되는 요소를 지질분야, 수리지질분야, 지화학분야 등으로 분류 하고 이들 각 분야별로 세부 항목에 대한 국외 기준 분석 을 수행하는 것을 목적으로 하고 있다. 본 논문에서는 그 첫 번째 단계로 지질분야의 세부 항목별 국외 기준분석을
수행하였다. 향후, 수리지질분야 및 지화학분야 의 세부 항목에 대해서도 국외 기준분석을 수행할 계획이다. 논문 결과는 향후 국내의 처분장 부지선정 기준 수립시에 중요 한 참고자료로 활용될 수 있을 것으로 판단된다.

\section{2. 용어 정의}

본 논문에서는 심지층 처분장 부지선정과 관련하여 부 지선정요소(Siting factor), 요건(Requirement), 선호조건 (Preference), 기준(Criteria), 지표(Indicator) 등의 용어 들이 사용되었다. 이들 용어들에 익숙하지 않은 독자들 의 혼란을 피하기 위하여 용어들에 대한 정의를 아래에 나 타내었다. 용어정의는 스웨덴 보고서[3, 4], IAEA Safety series[2] 및 국내 문헌[5]을 참고로 하였다.

○ 부지선정요소 (Siting factor) : 심지층 처분장 부지선정 작업에서 고려되는 지질평가요소(Geoscientific evaluation factor)를 의미한다. 본 논문에서는 심지층 처분 장 부지선정요소를 지질, 수리지질, 지화학 등으로 구 분하였다.

○ 요건 (Requirement) : 부지선정 단계와 관계없이 항시 만족하여야 하는 조건으로서, 심지층 처분장은 모든 요 건을 만족하여야 한다.

○ 선호조건 (Preference) : 부지선정 단계와 관계없이 만 족하여야 하는 조건이지만, 항시 만족할 필요는 없다.

○ 기준 (Criteria) : 개별 부지선정단계에서 부지적합성을 평가하기 위해 활용되는 부지선정인자에 대한 정량화 된 값 혹은 조건으로서, 부지선정 단계별로 다른 값 혹 은 조건이 적용될 수 있다.

○ 지표 (Indicator) : 측정 혹은 예측 가능한 인자로서 개 별 부지선정 단계에서 요건을 만족시키는지 여부를 판 단하는데 활용된다.

\section{3. 지질학적 부지선정요소}

심지층 처분장의 장기 안전성은 크게 공학적방벽과 자연 방벽에 의해 보장되며, 자연방벽은 처분되는 사용후핵연료 를 장기간 안전하게 격리하는 기능과 누출된 핵종이 생태 계로 이동되는 것을 지연시키는 역할을 수행하게 된다. 심 지층 처분장 부지선정에서는 이와 같은 자연방벽의 기능과 관련된 요소들을 중점으로 평가하여야 하며, 부지선정 과 정에서 이들 요소들에 대해 정량평가가 요구된다.

본 논문에서는 국내·외 문헌들과 관련 전문가들의 의 
견을 참고로하여 사용후핵연료 심지층 처분장 부지선정 에서 고려되는 중요한 요소 중 지질분야를 지형, 토양층, 암종, 구조지질, 역학적 안정성, 지질학적 사건(광역수직 운동, 활성단층, 지진, 화산)으로 분류하고 이와 관련한 국 외 부지선정기준을 분석하였다.

○ 지형 : 처분장이 위치한 암반의 격리기능과 지하수 유 동특성을 판단하는데 간접지표로 활용

○ 토양층 : 처분장 부지의 역학적 안정성을 평가하는데 활용

○ 암 종 : 처분장의 격리 및 핵종이동 지연기능에 큰 영향 을 미치는 요소

○ 구조지질(광역·국지규모, 부지규모, 소규모 단열) : 처 분장의 격리 및 핵종이동 지연기능 평가에 있어서 매우 중요한 요소

○ 역학적 안정성(초기 응력, 암반 강도) : 처분장의 격리기능 과 핵종이동 지연기능 평가에 있어서 매우 중요한 요소

○ 열적특성(열전달, 열적반응) : 처분장 배치와 설계 시 중 요한 요소

○ 지질학적 사건(광역수직운동, 활성단층, 지진, 화산) : 처 분장 부지선정에서 배제조건에 포함됨

\section{4. 지질요소 국외기준 분석}

지질조건은 대상지역의 역학적, 열적, 수리적 및 화학적 특성을 결정하는 중요한 요소이며, 부지에 대한 지구과학 적 이해의 기반이 된다. 또한, 심지층 처분장이 위치하는 지 역의 지질환경은 주 변형대가 없어야 하며, 처분장 완충재 가 격리 및 밀봉능력을 유지할 수 있도록 균질하여야한다.

국내·외 문헌들과 관련 전문가들의 의견을 참고로하여 사용후핵연료 심지층 처분장 부지선정에서 고려되는 지질 요소에 대해 심지층 처분장 부지를 선정한 스웨덴, 핀란드, 미국과 현재 부지선정 작업을 진행 중에 있는 스위스, 독 일, 영국, 일본 등에서 적용하고 있는 처분장 부지선정 기 준을 분석하였다. 또한, 정량기준에 대한 근거를 파악하기 위하여 추가적인 문헌조사를 수행하였으며, 결과를 정리 하였다.

스웨덴에서는 빙하 및 퇴빙 그리고 이로 인한 침식 등에 대 한 기준을 상세히 기술하고 있으며, 지진 및 화산활동이 활 발한 일본에서는 이에 대한 기술이 상대적으로 상세하게 정 리되어 있다. 이와 같이, 개별 국가 별로 중요하게 고려되고 있는 인자들을 중심으로 분석하였으며, 이를 정리하여 각
국가에 대해 비교·분석하였다.

\section{1 국가별 부지선정 절차 및 단계}

지질분야 부지선정요소에 대한 국외 문헌 분석에 앞서, 본 논문에서 분석한 스웨덴, 핀란드, 스위스의 부지선정 절 차 및 단계를 분석하였으며, 그 결과를 아래에 요약하여 나 타내었다.

\section{1 .1 스웨덴}

스웨덴에서는 심지층 처분장 부지선정은 크게 4단계로 구 성되어 있다. 〈단계 1〉은 일반연구 단계로서 전국규모 조 사 및 자료수집을 수행하며(1993 1998), 〈단계 2〉는 타당 성연구 단계로 지자체 범위에서 심지층 처분장 건설 가능 을 검토한다(1993 2000). 〈단계 3〉은 부지특성조사 단계 로서 선정부지에 심지층 처분시설 건설 가능 여부를 판단할 수 있는 자료확보를 위해 시추조사, 안전성평가, 환경영향 평가 등을 수행한다(2002 2007). 〈단계4〉는 상세조사 단 계로 결정된 심지층 처분장 부지에 대한 상세조사를 수행 한다(2011 2017).

\section{1 .2 핀란드}

핀란드의 심지층 처분장 부지선정 작업은 4단계로 구분할 수 있으며, 핀란드 의회는 2001년 올킬루오토 지역을 심지 층 처분장 부지로 승인하였다. 현재 처분기술 실증을 위한 지하연구시설 건설 작업을 수행하고 있다. 〈단계 1 〉은 광역 부지조사 단계로 전국규모의 조사를 수행하여 부지특성조 사를 위해 102개 지역을 선정한다(1983 1985). 〈단계 2〉는 부지특성조사 단계로 잠재적 기반암 지역에 대한 예비 부지 특성조사를 수행하여 부지를 5개로 줄인다(1986 1992).〈 단계 3>은 상세조사 단계로 부지특성조사로부터 선별될 지 역에 대한 상세 부지특성조사를 수행하여 부지를 4 개로 줄 인다(1993 2000). 〈단계 4〉는 부지확정 단계로 상세조사 를 통해 심지층 처분장 부지로 가장 적합한 지역을 선정한 다(1999 2001).

\section{1 .3 스위스}

스위스는 심지층 처분장 부지선정과 중저준위방폐물 처분 장 부지선정 작업을 동시에 수행하고 있으며, 부지선정 작 업을 3 단계로 구분하고 있다. 〈단계 1〉에서는 지질학적 입 지검토 지역을 선정하고, 〈단계 2〉에서는 처분장 부지를 최소 2곳 선정한다. 〈단계 3〉에서는 처분장 인허가 신청을 위한 부지 1곳을 선정한다. 2011년 12월 전담기관(Nagra) 
에서 〈단계 1〉 수행 내용에 대해 연방정부의 승인을 획득 하였다.

\section{2 지형}

지형(topography)이란 지구 표면의 특징적인 형태를 말하 며 지표의 고저기복, 즉 산 · 골짜기 · 평야 · 하천 · 해안 · 해저 등의 각종 지표형태를 말한다. 이러한 지형정보는 구 조(structure) 확인 및 수리 경계조건(hydraulic boundary condition) 구분 등에 이용가능하며 세밀한 지형 정보는 다 양한 규모의 단열 특성을 파악하는데 이용된다. 따라서, 처 분장이 위치한 암반의 격리기능과 지하수 유동특성을 판단 하는데 간접적인 지표로 활용된다.

스웨덴에서는 광역 규모에서 $0.1-1 \%$ 이내를 선호하며[4], 핀란드[6], 스위스[7], 독일[8], 영국[9], 미국[10] 및 일본[11] 에서는 가능한 한 낮은 지형경사를 나타내어야 한다.

\section{3 토양층}

표토층(Soil cover)은 처분장의 격리기능에 직접적인 영향 을 미치지는 않지만, 기반암이 무산소 조건을 유지하는데 큰 영향을 미치는 것으로 알려져 있다. 또한, 표토층에 대 한 연구결과는 해수면 변동 및 지진발생 등과 같은 신지구 조운동의 지표로 활용될 수 있으며, 신지구조운동의 발생 여부는 처분장 부지의 역학적 안정성을 평가하는데 있어서 매우 중요한 지표로 활용된다. 하지만, 표토층은 기반암 특 성평가에 있어서 제한요소로 작용하지 않는다.

스웨덴에서는 토양층의 두께 $20 \mathrm{~m}$ 이하를 선호하며[4], 핀 란드[6], 스위스[7], 독일[8], 영국[9], 미국[10], 일본[11]에서 는 토양층을 고려하지 않는다.

\section{4 암종}

암종에 따라 각기 다른 열적 및 역학적 특성(열전도도, 강도 등)을 나타내며, 이와 같은 특성으로 인해 암종은 심 지층 처분장의 격리 및 핵종이동 지연 기능에 큰 영향을 미 치는 요소로 알려져 있다. 스웨덴의 사용후핵연료 심지층 처분장 부지로 포스마르크(Forsmark)를 선정하는 과정에 서도 기반암의 열전도도가 큰 영향을 미친 것으로 알려져 있다[12].

암종 별로 각기 다른 변형 특성을 나타내며, 일반적으로 암종 경계는 상대적으로 강도가 약한 특성을 나타낸다. 따 라서, 심지층 처분장의 장기 안전성을 위해서는 균일 암종
으로 이루어진 기반암이 선호된다.

스웨덴에서는 화강암을 선호하며, 화산암, 퇴적암, 기타 암종을 비선호암종으로 분류한다[13]. 핀란드에서는 화강 암류(반암, 세립질 화강암, 화강편마암, 화강섬록암 등)를 선호하며[6], 약 5 6 $\mathrm{km}^{2}$ 의 적당한 크기와 균질성을 가져야 한다. 독일에서는 일정한 암종을 보이는 것이 좋고, 〈단계 2 조사에서 기반암의 두께는 $100 \mathrm{~m}$ 이상이고 기반암의 면 적은 암염의 경우 $3 \mathrm{~km}^{2}$ 이상, 점토층이나 결정질암의 경우 $10 \mathrm{~km}^{2}$ 이상이어야 한다[8]. 기반암의 깊이는 $500 ~ 1500 \mathrm{~m}$ 를 선호하고 적어도 300 500m 범위여야 한다[8]. 미국에서는 기반암내에 수리적 상호작용으로 인한 용해의 증거가 있는 경우는 배제하고, 기반암은 충분히 두껍고 수평적으로 광범 위하게 분포하여야 한다. 기반암의 깊이는 $300 \mathrm{~m}$ 이상이 선 호되고, 적어도 지하시설의 모든 부분이 지하 $200 \mathrm{~m}$ 이하에 설치되어야 한다[10]. 일본에서는 간극수압 및 팽윤성, 가스 함유량, 함수율이 낮거나 암석관입의 비율이 낮아야 한다. 변성/풍화의 정도가 작아야 하고, 지하시설을 수용할 수 있 는 충분한 깊이를 가진 지층이 넓게 분포되어야 한다[14].

\section{5 구조지질}

암반은 오랜 기간 동안 압력과 온도의 영향을 받아 부분 용 해되거나 변형 된다. 온도와 압력이 높은 심부에서는 취성변 형(brittle deformation) ${ }^{1)}$ 없이 소성변형(plastic deformation)이 발생한다. 소성변형은 높은 온도와 압력하에서 발 생하며, 일반적으로 심부 기반암에서 생성된다. 소성변형 을 통해 생성되는 소성구조는 습곡(folds), 엽리(foliation), 선구조(lineation), 광맥(veining) 등이 있다. 또한 소성변형 을 통해 암석의 변성작용으로 편마암(gneiss)이 형성되며 지속적으로 압력을 받는 소성전단대(plastic shear zone)에 서는 호상구조(Banded)2) 가 형성된다. 또한 단층(fault)과 함께 호상구조를 통해 압쇄암(Mylonite)이 형성된다. 소성전단대를 나타내는 기반암은 처분장 안전성과 관련하 여 다음과 같은 특성을 나타낸다.
대규모 변형대
$\circ$ 비균질 기반암
애대규모 지하수 유동 경로

\footnotetext{
1) 취성(brittle) : 외부에서 힘을 받았을 때 물체가 소성변형을 거의 보이지 아니하고 파괴되는 현상

2) 호상구조 : 색을 달리하는 광물들이 층상으로 번갈아 배열하여 만들어지는 평행구조
} 
따라서 소성전단대는 처분장 부지의 격리기능과 핵종이동 지연 기능 평가에 있어서 매우 중요한 요소로 고려된다.

단열대(fracture zone)는 취성암반의 변형에 의해 발생하 며, 상대적으로 온도 및 압력이 낮은 지각 상부에서 형성된 다. 단열대는 모암에 비해 상대적으로 높은 수리전도도와 낮은 강도특성을 나타낸다.

소성변형과 취성변형을 명확히 구분하기는 불가능하며, 변형대에 대해서 다양한 명칭으로 구분하고 있다. 단층 (fault)은 변위가 발생한 단열대를 의미한다.

\subsection{1 소성구조}

핀란드에서는 암석관입 지역은 예비조사단계에서 배제 한다[6]. 스웨덴에서는 〈단계1>에서 $30 \mathrm{~km}$ 이상 선구조에 대한 선구조밀도도를 작성하여 분류한다[13]. 〈단계2〉에서 알려진 광역연성전단대는 피하고 만약 충분한 처분장 공간 이 없는 경우에는 배제한다. 〈단계3〉에서는 상세하게 조사 된 광역연성전단대를 따라 처분장의 배치를 수정하고 합리 적으로 배치할 수 없는 경우 배제한다. 독일에서는 〈단계 2) 조사에서 암석관입의 가능성이 없어야 하고 방벽역할 을 하는 상부지층 두께는 $150 \mathrm{~m}$ 이상이 선호되고, 적어도 $100 \mathrm{~m} 150 \mathrm{~m}$ 는 되어야한다[8]. 미국에서는 소성구조가 폐 쇄후 향후 1 만년 동안 인접환경에 핵종을 유출시킬 확률이 $1 / 10,000$ 이하이면 선호하고, 만약 지하수 유동 시스템에 영향을 주는 경우는 배제한다[10]. 일본에서는 지난 수십년 간 큰 활동을 보인 활성습곡 및 요곡 지역은 배제한다[11].

\subsection{2 취성구조}

스웨덴에서는 〈단계 1 >에서 단층대 분포조사를 하나 현장조사 없이는 배제지역으로 구분하지 않는다[4]. 〈단계2〉에서 파악된 단열대와 충분한 거리에 있어야 한다. 단열대가 많아서 처분장이 부적절하게 분리될 경우는 배제지역으로 구분한다. 〈단계3〉에서 광역 주 단열대와 국지 주단열대로부터 수십m이상, 광역주단 열대로부터 $100 \mathrm{~m}$ 이상 떨어져야 한다. 만약 처분장이 광역 주단열대, 국지 주단열대 때문에 합리적으로 위 치할 수 없다면 배제지역으로 구분한다. 독일에서는 〈단계2〉에서 단층과 단층의 간격은 $3 \mathrm{~km}$ 이상이 선호 되고 적어도 $100 \mathrm{~m} 3 \mathrm{~km}$ 범위여야 한다[8]. 미국에서 는 취성구조가 폐쇄후 향후 1 만년 동안 인접환경에 핵 종을 유출시킬 확률이 $1 / 10,000$ 이하인 지역을 선호 하고, 만약 지하수 유동 시스템에 영향을 주는 경우는 배제한다. 또한, 방사성폐기물 격리에 손실을 발생시 킬 것으로 예상되는 경우도 배제한다[10].

\section{6 역학적 안정성}

역학적 안정성이란 암반의 완충작용을 통해 처분용기가 암반의 움직임(movement)으로부터 안전하며 새로운 단열 로 인한 지하수유동의 영향을 받지 않는 것을 의미한다. 따 라서, 암반의 역학적 안정성은 심지층 처분장의 격리기능과 핵종이동 지연기능에 영향을 미치게 된다.

처분장 규모에서 암반의 안정성은 열적 변화(thermal change), 동적하중(dynamic loads), 하중상태에서 광역적 변화(예, 빙하)등의 결과로 분석한다.

\subsection{1 초기응력}

스웨덴에서는 〈단계3〉에서 만약 처분장이 암반 초기 응력 에 의해 발생하는 박리작용이 광범위하게 일어난다면 배제 지역으로 구분한다[4]. 영국에서는 암반 초기응력은 1 차 배 제조건 적용 후에 고려하며[9], 일본에서는 지층처분을 행하 려고 하는 지층과 그것을 둘러싼 지층에 대해서 암반의 강 도가 낮지 않아야 한다[11].

\subsection{2 암반강도}

스웨덴에서는 〈단계2〉에서 암종에 따라 추측된 압축강도 를 근거로 평가하며 배제조건으로 고려하지 않는다[4]. 〈단 계3>에서 암석의 압축강도가 스웨덴 기반암의 평균치에서 많이 벗어난다면 특별한 주의가 필요하다. 독일에서는 〈단 계2>에서 처분장은 암반의 압축강도에 따른 최대 허용깊이 를 나타내는 그래프의 기준선 아래 또는 기준선 위 $10 \%$ 이내 의 범위에 위치해야 한다. 〈단계2〉에서 인장강도가 $100^{\circ} \mathrm{C}$ 기준 화강암은 $13 \mathrm{MPa}$ 이상이고, 점토암은 $8 \mathrm{MPa}$ 이상, 암 염은 $2 \mathrm{MPa}$ 이상일 경우 선호하고 적어도 화강암은 $8 \mathrm{MPa}$ 이 상이어야 한다[8].

\subsection{3 기체발생에 의한 압력 증가}

스위스에서는 〈단계 2〉에서 기체가 방벽에 영향을 미치 지 않으며, 기반암으로부터 방출되고 발생된 기체에 대한 공학적 조치가 필요 없을 경우 매우 적합으로 하고, 공학적 조치가 필요한 경우는 적합한 것으로 판단한다[7]. 독일에 서는 〈단계 2〉에서 기체투과도가 $10^{-9} \mathrm{~m} / \mathrm{s}$ 이상일 경우 선 호조건으로 한다[8].

\section{7 열적 특성}

심지층 처분장에서 예상되는 온도는 역학적 환경, 지하수 유동, 화학적·생물학적 환경에 영향을 미치기 때문에 처분 장의 배치와 설계 시 중요한 요소로 고려된다. 
열은 열전도(heat conduction) 뿐만 아니라 이류(advection)를 통해 전달될 수 있다. 공극률이 높을 경우에는 지하 수의 이류작용이 중요하지만 균열암반에서는 열전도가 주 요한 전달 메카니즘이나 $10^{-3}$ 에서 $10^{-4}$ 사이의 공극률을 보 일 경우 무시할 수 있다. 열전달(heat transport)은 열전도 도, 밀도, 암반의 열용량에 의해 결정된다.

\subsection{1 열전달}

스웨덴 기반암의 열전도도의 평균값은 $2.6 ~ 3.7 \mathrm{~W} / \mathrm{mK}$ 이 며, $2.5 \mathrm{~W} / \mathrm{mK}$ 이상을 선호한다[4]. 열팽창계수는 〈단계 3〉 에서 분석한다. 미국에서는 높은 열전도율와 낮은 열팽창율 을 가진 기반암을 선호한다[10].

\subsection{2 열적반응}

스웨 덴에서는 기반암 주위온도는 최대 $100^{\circ} \mathrm{C}$ 미만이어야 하고 지열에너지 방출 잠재력이 클 것으로 평가되는 지역은 배제한다[4]. 독일에서는 〈단계 2〉에서 기반암내 광물의 반 응이 시작되는 온도가 $120^{\circ} \mathrm{C}$ 이상일 경우를 선호하며, 적어 도 $100 \sim 120^{\circ} \mathrm{C}$ 범위이어야 한다[8], 또한 열로 인한 교란 범 위는 $10 \mathrm{~m}$ 이하를 선호하며, 적어도 10 50m 범위이어야 한 다. 미국에서는 방사성폐기물에서 발생된 열에 의해 변화된 모암과 주변 지역의 지질학적 구조, 지화학적, 열적, 수리학 적 특성이 모암에 의한 지연효과를 심각하게 감소시키는 경 우는 배제한다[10]. 또한, 열에 기인한 균열이나 광물의 수 화작용이나 탈수작용, 염수 이동 등 물리적/화학적/방사성 적 작용으로 안해 저장 및 격리가 영향을 받을 것이라 예상 되는 경우는 배제한다.

\section{8 지질학적 사건}

\subsection{1 광역수직이동}

자연발생적 수직운동이 있고 동시에 침식이 발생한다 고 가정하면 1 년에 $1 \mathrm{~mm}$ 의 지구조 융기는 백만 년 안에 $1,000 \mathrm{~m}$ 깊이의 처분장을 노출시킨다. 따라서, 광역수직운 동은 기반암의 격리 및 핵종이동 지연 기능에 매우 큰 영향 을 미치게 되며, 광역 규모에서 처분장 건설에 부적절한 지 역을 확인할 경우 1 년에 $1 \mathrm{~mm}$ 이상 규모로 광역적인 자연 발생 융기를 하는 지역은 처분장 부지 선택에서 제외하여 야 한다.

스웨덴에서는 퇴빙에 의한 융기로 인해 처분장이 영향을 받지 않는 깊이는 지하 $500 \mathrm{~m}$ 로 정의하였다[13]. 핀란드에서 는 처분장 안전성에 있어 빙하로 인한 침식은 중요한 영향을 미칠 것으로 생각되지 않으므로 부지 선정 시 고려하지 않는 다[6]. 독일에서는 연평균 $1 \mathrm{~mm} / \mathrm{yr}$ 이상 대규모 융기작용이
발생하지 않아야 하며[8], 영국에서는 지역에 따라 차이가 나 므로 초기 배제조건에서 고려하지 않고 후속 부지특성조사 에서 고려한다[8]. 미국에서는 융기·침강 및 침식·퇴적으 로 인하여 폐쇄후 향후 1 만년 동안 인접환경에 핵종을 유출 시킬 확률이 $1 / 10,000$ 이하이면 선호하고, 만약 지하수 유동 시스템에 영향을 주는 경우는 배제한다[10]. 일본에서는 십 만년 동안 $300 \mathrm{~m}$ 이상 융기된 지역과 십만년동안 $300 \mathrm{~m}$ 이상 침식된 지역은 배제한다[11].

\subsection{2 활성단층대}

활성단층은 지질학적 시간으로 최근(3만5천년)에도 계속 운동하는 것으로 예상되는 단층으로 소규모의 주 기적 변위나 지진활동이 일어난다. 하지만, 기존 연구 에 의하면 단층이동에 의해 야기되는 지진은 심지층 처분장 깊이(약 $500 \mathrm{~m}$ )에서는 큰 영향을 미치지 않는 것으로 보고되고 있으며, 이로 인한 지하수 화학 변화 도 처분장의 성능평가에 장기적 영향은 미미한 것으로 알려져 있다.

독일에서는 〈단계 1 〉에서 처분장 부지내에 활성단층 이 없어야 하며, 영국에서는 초기 배제조건에서는 고 려하지 않고 후속 부지특성 조사에서 고려한다[8]. 일 본에서는 전국 규모에서 확인되는 활성단층지역은 배 제한다. 전국 규모가 아닌 다른 문헌에 조사된 활성단 층지역, 활성단층의 변형대주변과 파쇄대(가우지, 각 력암, 압쇄암 등), 활성단층의 분기가 발생할 가능성이 높은 지역은 배제한다[11].

\subsection{3 지진활동}

스웨덴에서는 〈단계 1>에서 1375 1993년 사이의 역사지진 분포도를 작성하지만 배제조건으로 고려하지 않는다[4]. 독 일에서는 〈단계 1〉에서 DIN 4149 기준 지진영역 1을 넘지 않 아야 하며[8], 영국에서는 초기 배제조건에서는 고려하지 않 고 후속 부지특성 조사에서 고려한다[9]. 미국에서는 대규모 지진기록이 있는 경우, 빈번한 지진발생 또는 대규모 지진 발 생의 징후가 있는 경우는 배제한다[10]. 일본에서는 초기 부 지를 선택할 때는 고려하지 않고 다른 지역과 안전성을 비교 하는 PIA와 DIA 조사에서 고려한다[11].

\subsection{4 화산활동}

화산활동이 일어날 경우 마그마의 관입, 분출로 인해 처분장 과 그 주변 암반이 파괴되어 방사성핵종을 지표로 방출할 가 능성이 있다. 또한 화산활동에 의한 열, 열수의 방출은 주변암 반 변질이나 수리특성의 변화를 일으키며, 열수 대류는 핵종 
이동을 촉진 시킬 가능성이 있고 열수, 화산가스의 혼입에 따 른 지하수의 수질변화나 열적영향은 공학적방벽의 성능저하 를 일으킬 가능성이 있다. 따라서, 화산활동은 처분장의 장기 안전성에 큰 위해요소로 작용할 수 있다.

독일에서는 〈단계 1 >에서 처분장 인근 $10 \mathrm{~km}$ 범위 이내 는 제 4 기 또는 향후 화산활동이 예측되지 않아야한다[7]. 미 국에서는 화산활동이 지하수 유동 시스템에 영향을 주는 경 우는 배제한다[9]. 일본에서는 화도(Volcanic vent) 주변 반 경 $15 \mathrm{~km}$ 이내는 배제하고, 수만년내 마그마 관입 또는 분 출이 예상되는 지역과 열적 영향, 높은 산성온천, 지하수 의 열수순환이 예상되는 지역은 $15 \mathrm{~km}$ 밖의 지역이라도 제 외한다[11].

\section{5. 결 론}

심지층 처분장 부지선정요소(Siting factor)에 대한 기준 (Criteria)은 주로〈사업단계〉에서 활용되며, 본 논문에서 참고한 많은 국외 문헌들도 〈사업단계〉에 접어든 국가들을 중심으로 분석하였다. 이미 언급한 바와 같이, 국내에서는 정확한 심지층 처분장 부지선정 절차가 확정되지 않아 〈사 업단계>에서 활용되는 부지선정요소(Siting factor)에 대한 기준을 설정할 수 없는 실정이다. 하지만, 본 논문에서는 향 후 활용가능성을 염두에 두고 심지층 처분장 부지선정 〈사 업단계〉에 접어든 국가들을 중심으로 지질 관련 부지선정 요소를 〈사업단계〉 별 적용가능한 기준을 분석하였다.

부지선정요소에 대한 기준은 각 국가가 처한 지질환경에 따라 다른 조건 혹은 값을 제시하고 있다. 예로, 화산 및 지 진활동이 빈번한 일본에서는 이에 대한 기준을 상대적으로 상세히 기술하고 있으며, 빙하작용이 예상되는 스웨덴에서 는 빙하작용에 의한 지반 융기 · 침식에 대한 영향을 상세히 분석하였다. 따라서, 국내에서는 다양한 지질환경에 대해 폭넓은 기준을 참고로하여 국내 지질환경에 적합한 부지선 정요소에 대한 기준을 제시할 수 있을 것으로 판단된다.

\section{REFERENCES}

[1] KRMC. Analysis of Site Selection Process of Overseas Geological Repository, 14215-K-TR-001(2011).

[2] IAEA. Siting of Near Surface Disposal Facilities, Safety series No. 111-G-3 1(1994).

[3] SKB. Geoscientific Evaluation Factors and Criteria for Siting and Site Evaluation, SKB R-99-07(1999).
[4] SKB. What Requirements does the KBS-3 Repository make on the Host Rock?, SKB TR-00-12(2000).

[5] S.H. Lee and Y.S. Hwang, "Technical Standards on the Safety Assessment of a HLW Repository in Other Countries", J. of the Korean Radioactive Waste Society, 7(3), pp. 183-190 (2009).

[6] POSIVA, The Site Selection Process for a Spent Fuel Repository in Finland-Summary Report, (2000).

[7] Nagra. Darlegung der Anforderungen, des Vorgehens und der Ergebnisse, NTB 08-03(2008).

[8] AkEND, Site Selection Procedure for Repository Sites, Recommendations of the AkEnd - Committee on a Site Selection Procedure for Repository Sites, AkEnd(2002).

[9] DETEC, Sectoral Plan for Deep Geological Repositories, Conceptual Part, Department of the Environment, Transport, Energy and Communications (DETEC) (2008).

[10] US NRC, 10. 10CFR Part 960.

[11] NUMO. EFQ: Evaluation Factors for Qualification; Siting Factors for the Selection of Preliminary Investigation Areas(2002).

[12] SKB. RD\&D Programme 2010. Programme for Research, Development and Demonstration of Methods for the Management and Disposal of Nuclear Waste, TR-10-63(2010).

[13] SKB. General Siting Study 95, Siting of a Deep Repository for Spent Nuclear Fuel, SKB TR-9534(1995).

[14] NUMO, Evaluating Site Suitability for a HLW Repository, NUMO-TR-04-04(2004). 